\title{
Activités
}

\section{Activity theory as a supportive framework in design of navigation equipment}

La théorie de l'activité comme aide à la conception d'équipement de navigation

La teoría de la actividad como soporte para el diseño de equipos de navegación

Cato Alexander Bjørkli, Bjarte Knappen Røed, Hans Vanhauwaert Bjelland, Kristian Gould and Thomas Hoff

\section{(2) OpenEdition}

\section{Journals}

Electronic version

URL: http://journals.openedition.org/activites/1484

DOI: $10.4000 /$ activites. 1484

ISSN: $1765-2723$

Publisher

ARPACT - Association Recherches et Pratiques sur les ACTivités

\section{Electronic reference}

Cato Alexander Bjørkli, Bjarte Knappen Røed, Hans Vanhauwaert Bjelland, Kristian Gould and Thomas Hoff, "Activity theory as a supportive framework in design of navigation equipment », Activités [Online], 4-1 | avril 2007, Online since 15 April 2007, connection on 19 April 2019. URL : http:// journals.openedition.org/activites/1484; DOI : 10.4000/activites.1484

\section{c) (†) $\ominus$}

Activités est mis à disposition selon les termes de la licence Creative Commons Attribution - Pas d'Utilisation Commerciale - Pas de Modification 4.0 International. 


\title{
Activity theory as a supportive framework in design of navigation equipment
}

\author{
C.A. Bjørkli", B.K. Røed ${ }^{\mathrm{b}}$, H.V. Bjelland', K.S. Gould', T. Hoff ${ }^{\prime}$ \\ a Department of Product Design, Norwegian University of Science and Technology, 7491 Trondheim, Norway \\ Department of Psychology, Norwegian University of Science and Technology, 7491 Trondheim, Norway \\ 'Section for Occupational Medicine, Faculty of Medicine, University of Bergen, 5018 Bergen, Norway \\ ${ }^{d}$ Department of Psychology, University of Oslo, Blindern, 0317 Oslo, Norway
}

\begin{abstract}
This study reports on the use of Activity Theory as a supportive framework in a design process. Crews on Fast Patrol Boats in the Royal Norwegian Navy were observed during high-speed navigation in coastal waters. The unit of analysis was the navigation team of five persons in their work. Activity was regarded as situated actions shaped by tools, objects and constraints. The framework of Activity Theory was used to form a design language that encompassed the aspects relevant to design and navigation. Based on the findings, a prototype of a automated steering system was built. We suggest that in design process, Activity Theory moves the focus from the technical qualities of artefacts towards how artefacts are used as tools to mediate activity.
\end{abstract}

Keywords

Activity theory, design, ships, navigation

\section{1.- Introduction}

A team working on the ship's bridge navigates the ship by cooperation and operation of advanced equipment in order to proceed safely. A ship is a here considered a dynamic system as it is heavily influenced by environmental factors such as weather, wind, and visibility conditions.

During the last 10 years automated systems has largely been utilized in operations of ships. Despite the complexity of modern ships, the design of the bridge layout and navigation artefacts is traditionally not subject to any explicit design process. Safe operations are established through the fulfilment of technical and functional demands stated by classification societies and international organizations.

Technology driven design narrows the designers' focus to technical features of the single artefact, rather than focusing on its actual use. By using Activity Theory (AT), we wanted to expand focus to describe how artefacts have more than technical and formal qualities. This study will investigate how such an approach can shape design.

Design approaches commonly emphasize the need to understand the context in which products are to be used. However, these approaches are primarily ways to identify and organize steps in a design process, rather than research-based theoretical frameworks that guide in how to describe context of use. Support from AT may augment design approaches by providing tools for understanding the meaning and implication of the context.

In a design process, AT intends to bridge the gap between descriptions of work and the design of artefacts. This is a large step that can be taken as two smaller steps. First, AT can be used to give a description of work. Second, AT can contribute to a design language, which represent those aspects of work that matter to design (Beyer, \& Holzblatt, 1998). This paper primarily concerns the latter aspect, but the forming of a design language is based on a more comprehensive AT study of navigation 
(Bjorkli, Roed, \& Hoff, 2006). In the following, the framework of AT is described, but limited to the aspects of the framework that were used for design purposes.

\section{1.-Activity Theory}

The underlying model of activity is based on Engeström's complex model of an activity system (Engeström, 1999). Originally Engeström emphasizes the cultural and historical influence on activity. To model behaviour generating mechanisms in maritime navigation, we regard activity as situated actions taking place over shorter periods of time. The situated actions model of activity also includes constraints as adopted from Norros (Norros, 2004). The model is shown in figure 1. By this approach, we have deemphasized factors of longer-term influence such cultural aspects and development of habits.

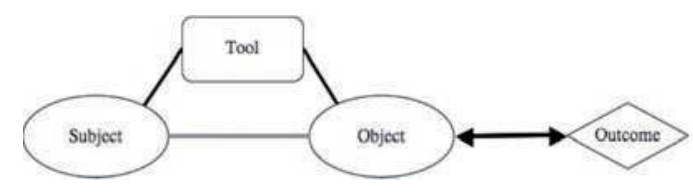

Figure 1: Representation of situated actions

The subject is a person or group in the activity. The Object is what directs the activity. The subject does not directly relate to the object, but relates indirectly through the use of tools.

The tools are used to mediate activity towards the object. This study emphasizes two forms of mediation (Rabardel, \& Béguin, 2005):

Reflexive mediation refers to creating relations between the tools and the subject, and how the subject uses tools for support. Examples are how people use colour codes in software applications to memorize the state of ongoing processes.

Inter-personal mediation concerns mediated relationships to others. Examples are computer programmes were people elaborate on other persons' previous work.

The object is transformed into some form of outcome. The model has a two-way arrow between the object and the outcome, where the outcome also influences the object. This mutual relationship is shaped by constraints. Constraints are system-dependent functional characteristics of the environment. Subjects in different systems (e.g. different vessel classes) operate under different constraints (Bjørkli, Roed, \& Hoff).

In the real world, change and development are distinct features of the activity. The term tensions are used to describe the misfit or conflict in relation to other activities or within the development of a single activity. In this sense, activity systems unfold through the resolution of tensions.

The last point made here is about the hierarchical structure of activity (Ruutti, 1996). At the top of the hierarchy is activity, which is always directed towards a motive. Subordinate to activities are actions. Actions are directed towards conscious goals, where a goal is structured by a mental representation of the result to be achieved (Leontev, 1974). Goals are reached by sequences of actions, and are realized through operations that correlate with the actual conditions of the activity.

\section{2.- Methods}

In order to gather knowledge on activity of navigators and the use of navigation equipment, a case study was conducted on board Norwegian Fast Patrol Boats (FPB). Two crews were studied during naval exercises in 2003 and 2004. Direct and indirect observation was conducted, in total 120 hours of video was gathered. Semi structured interviews with navigators were carried out. 


\section{3.- Results}

The Hawk-class FPB is 36.5 meters long, 6.2 meters wide, and reaches a speed exceeding 30 knots (15.4 meters/second) (RNoN, 2006). The ship is designed and built for high-speed navigation in confined waters. The main tasks of the vessel is patrolling and upholding national presence in inshore waters. The FPBs are navigated by a team of five persons, working on the bridge of the ship.

The tasks of the ship require several activities to be conducted simultaneously. In our study, we will limit the focus to the activity of navigation, which is the unit of analysis.

The subject of our study is the navigation team consisting of five persons; the lookout, the helmsman, the plotter, the commanding officer, and the navigator. An overview of their workspace is shown on figure 2.

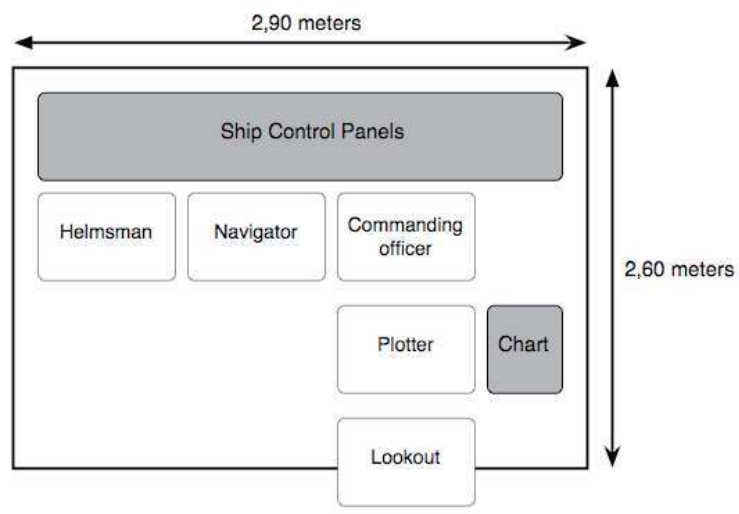

Figure 2: Overview of the crew's workplace.

The navigator is the kingpin of the team. He is responsible for planning and executing the voyage. When planning, the navigator draws lines in the paper charts representing the track to be followed. When navigating, the navigator aims to follow the planned track, and the navigator is assisted by the plotter. The plotter communicates information from the paper chart. The lookout is situated outside the bridge house and reports issues that the navigator should be aware of, such as lighthouses and other vessels. The helmsman steers the ship according to direct commands from the navigator. The commanding officer has the overall responsibility of the ship. When present on the bridge, he usually supervises and controls the performance of the team.

Navigation encompasses both position fixing and manoeuvring. Position fixing is about knowing the position of the ship. The navigator and the plotter cooperate in order to have continuous knowledge of the ship's position. Manoeuvring is about directing the movement of the ship in terms of speed and heading. The navigator regulates the speed, and gives verbal orders to the helmsman of what specific rudder angles or heading to steer.

The object of the team can be explained by reference to the hierarchal structure of activity. The motive of the activity is to follow the planned track. Subordinated to the motive are the actions. The most prominent actions are to direct the heading of the ship, control the speed, take positions, and plot the vessels progression. The persons on the navigation team carry out these actions individually. The actions are carried out by operations, which are done through the use of artefacts.

The most used artefacts are the wheel and compass, used by the helmsman for steering. Further, the navigator controls the speed by regulating the engines, using throttle levers. The navigator also operates the optical bearing device for fixing the ships position. The plotter works with the paper chart using pencils and rulers. The CO's most prominent tool is the radar situated in front of his work place.

The navigation team direct their work to transform the object of safe and efficient travel into the outcome of specific movement of the ship. 


\section{1.-Dynamics of navigation}

Navigation is a dynamic activity, and there are always tensions present. These tensions can have a small or large impact on the activity. Before we describe tensions' influence on the activity, the dynamics of navigation will be commented upon.

The planning of the navigation is conducted when the ship is secured at port. From the moment the ship leaves harbour, the navigation plan is effectuated. Meeting other vessels can hardly be planned beforehand, but must be included in the navigators execution of the plan. For the navigator to achieve and hold an internal representation of the plan, it is continuously communicated with the plotter and the lookout.

The navigation plan, externalized in the chart, is a tool used for inter-personal mediation, where the plotter elaborates on the previous work of the navigator. The course and distance to sail is constantly communicated between the navigator and the plotter. At regular intervals, the plotter calculates the position of the ship in the chart, and estimates the future positions. When the navigator has received and understood the information given to him, he acknowledges. If the navigator is in doubt about the meaning of the information, he asks the plotter to repeat or verify. When the navigator and the plotter discuss upcoming parts of the voyage, the chart serves as a common frame of reference.

A particular way of reflexive mediation is the navigator's use of the optical bearing device. In navigation, upcoming courses area often cued by characteristics in the environment. For example, a specific heading of a lighthouse in relation to the ship may cue an upcoming course transition. The navigator may then in advance direct the bearing device so that it points to where the lighthouse will become visible in accordance to the navigation plan. This forecasting of the direction where an environmental characteristic will appear is used to effectively find and identify the course transition cue. An advantage is that the navigator does not have to hold the next course in his working memory as he could just read the course on the bearing device's display. Further, he could let the tool figuratively represent the direction instead of remembering the next course as a three-digit number. First, he could get a general notion of the next course by roughly estimating the angle of the optical bearing device. Secondly, he could read the exact course by viewing the display. The information of the next course is not just externalised from the short time memory, but also given a figurative and spatial representation by the actual position of the pointing device.

Just as the chart, the bearing device offloads memory of detailed information. In addition, they also carry with them a forecast of activities to come. The chart forecasts in longer timeframes (e.g. the whole journey), whereas the optical bearing device forecasts in shorter timeframes. (e.g. next course or next navigation object to be used).

\section{2.-Serious tensions}

The activity can become entangled in a sequence where the activity is "going sour" when faced with serious tensions. This means that minor and unproblematic tensions come together and form a breakdown (Woods, \& Sarter, 2000). We will in the following describe a situation were several tensions surfaced and threatened the activity.

The factors described corresponds to how the navigation team interacted with different types of tensions; environmental constraints, external and internal tensions.

Environmental constraints, such as daylight, influence the activity. This is demonstrated by the following example. Reference points for position fixing were not visible due to darkness and snowy weather. This led to uncertainty about the ship's position. The navigator realised this, but decided that the ship's position was accurate enough for continuing the navigation. In the next five minutes, this led to an activity breakdown. The ship's position was not able to be determined, and the situation became more and more uncertain. Eventually the navigator prepared to stop. 
The sequence was made even more complex because a meeting ship had to be cleared, and this forced the navigator to deviate from the planned track. A third internal tension was connected to the technical status of the ship, as a critical alarm was sounded on the bridge.

All tensions occurred simultaneously, and their total impact on the activity can be described by the hierarchical structure of activity.

When minor tensions were present, the activity was carried out as operations. When tensions came into play, the activity took the form as actions directed towards conscious goals. As an example, when the ship's position were uncertain the navigator took the radar into use and estimated the ship's position based on radar measurements. During this work it was necessary to work consciously on the radar. Communication between navigator and plotter became more ad-hoc based, rather than procedural. The team also shed certain tasks, such as communication with persons outside the team. Equipment were re-configured, the engine controls were put to manual operations since this would allow the ship stop in a shorter distance.

At the peak of the episode the navigator had to deviate from the planned track, which meant that the activity could not longer be directed towards the motive. The navigator then established a new motive, and directed the activity towards keeping the ship in safe waters for a time long enough to get a position fix. The object was to avoid a basic constraint, solid land. After the ship's position was found, the activity again was directed towards the planned track.

The description of navigation has focused on the dynamic aspects of the activity, and how artefacts fill their mediating role. Tensions are always present and shape the activity, and thereby also the persons' use of artefacts. In the following, the description of the activity will form a basis for design of an artefact for supporting the navigation team.

\section{4.- Design}

AT was used to support design of an automated steering system. This kind of steering system is frequently used on modern high-speed craft, and will be taken into use on the next generation FPBs. Here, a course- and track pilot will replace the helmsman. This system can steer the ship on a given course, like a helmsman, or the system can make the ship follow a planned track, combining Global Position System (GPS) data with steering data. These two modes are called course mode and track mode.

AT was used to support design of an automated steering system. This kind of steering system is frequently used on modern high-speed craft, and will be taken into use on the next generation FPBs. Here, a course- and track pilot will replace the helmsman. This system can steer the ship on a given course, like a helmsman, or the system can make the ship follow a planned track, combining Global Position System (GPS) data with steering data. These two modes are called course mode and track mode.

When proceeding from the description of navigation and to design of specific artefacts, AT contributed to a design language reflecting what mattered in FPB navigation and what mattered in design.

\section{The Slider}

The design result was The Slider, as seen on figure 3. 


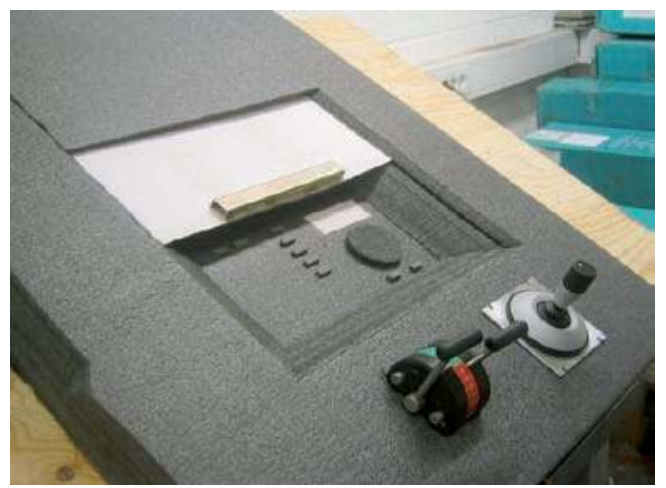

Figure 3: The Slider, course- and track pilot

A sliding curtain regulates the access to the functions and interface of the course- and track pilot. The pilot can be operated in three modes; in fully manual mode the curtain is all down, hiding all functions of the autopilot. The functions then visible are the least automated controls, the throttle for controlling the engine, and the joystick for controlling the heading of the ship. When the curtain is raised to half open, as on the figure, the interface of the course pilot is revealed. The curtain must be fully opened to reveal the track pilot interface. Changing the position of the curtain automatically switches mode.

The course- and track pilot is a tool for mediate steering of the ship. The pilot should be easy to operate in order to support its mediating role. The structure in which information is embedded should be easily available by avoiding menus and submenus.

The Slider clearly communicates its status as there is a distinct representation of the three different modes. In order to change mode, one physically operates the artefact. The levels of automation are clearly represented to enable communication about the given automation level. Change of automation level is as well clearly represented.

A course- and track pilot has a highly automated function enabling the ship to follow a planned route. This opens for tensions connected to technical issues. The pilot should therefore have different levels of automation, and the least automated level should correspond to the basic constraints of the activity. For a ship, that is to avoid solid land by controlling engine thrust and steering heading.

\section{5.- Discussion}

In this study AT provided a framework that coherently described the persons involved in FPB navigation, their use of tools, and what directed their behaviour. Further, AT provided a basis for a design language that was used in design of a course- and track pilot. The AT framework argues that an artefact encompass qualities beyond formal technical attributes.

AT are described as an attempt to integrate three perspectives; the objective, the ecological, and the sociocultural (Kaptelinin, 1996). In our study the latter perspective is downplayed. Literature (Perrow, 1984; Norros, 2004) has described that longer-term formations influence navigation safety. We recognize that longer-term formations are highly relevant, however they are outside the scope of this design study.

AT is a highly descriptive framework, and descriptive methods in design work have some weak points. A new design will influence the activity, which again will demand a new design. This is called the task-artefact cycle (Carroll, Kellogg, \& Rosson, 1991). One way of overcoming the task-artefact cycle is to describe the structures of the activity rather than the particular and artefact specific tasks that are carried out (Vicente, 1999). For this reason the design language should have the power to make inferences (Halverson, 2002). 
This study argues that using AT can bring important inputs to a design process. However, there is no 1:1 mapping between the theoretical descriptions of the domain and the design solutions. Descriptions provide a solution space including several possible design solutions. Proceeding from description to design involves a "magic step" where one or more solutions are chosen.

Because theoretical findings do not directly imply a specific design, one could argue that other approaches could lead to the same design. Several design guidelines such as Norman's seven principles (Norman, 1988) and Nielsen's design heuristics (Nielsen, 1993) embed several of the qualities that the Slider represents. However, this study claims that there are issues that are specific to the activity. Design guidelines and heuristics are general. To capture specific issues, there is a need for a framework that focuses the important structures of the activity in question. However, AT should not be an isolated tool, but should be regarded as one way of improving a design process.

The Slider has not been user-tested or evaluated in other ways. The purpose of our design was to suggest improvements to a system. The design of the slider can in this sense be regarded as a hypothesis of how a course- and track pilot can be designed. Further work on the design of the course- and track pilot should iterate between evaluation and design.

\section{6.- Conclusion}

This study argues that AT findings can contribute to design of navigation equipment. AT provides a framework that can be used to capture specific issues of the domain in study. The unit of analysis directs the focus to how artefacts are used as tools, and provides a framework for describing how artefacts have qualities beyond the formal technical attributes. Terms from AT can contribute to a design language, in order to support design.

\section{RÉFÉRENCEMENT}

Bjørkli, C.A., Røed, B.K., Bjelland, H.V., Gould, K.S, \& Hoff, T. (2007). Activity theory as a supportive framework in design of navigation equipment. @ctivités, 4 (1), pp. 179-187, http://www.activites.org/ v4n1/v4n1.pdf.

\section{REFERENCES}

Beyer, H, \& Holzblatt, K. (1998). Contextual design. Morgan Kaufmann Publishers.

Bjørkli, C.A., Øvergård, K., Røed, B.K., \& Hoff, T. (2006). Control Situations in High Speed Craft Operation. Cognition, Technology \& Work (in press) DOI: http://dx.doi.org/10.1007/s10111-006-0042-z

Bjørkli, C.A., Roed, B.K., \& Hoff, T. (2006). Using Activity theory for supporting navigation equipment in high speed craft. Manuscript submitted for publication.

Carroll, J.M., Kellogg, W.A., \& Rosson, M.B. (1991). The task-artefact cycle. In J.M. Carroll (Ed.), Designing Interaction: Psychology at the human-computer interface (pp. 74-102). Canbridge, England: Cambridge University Press.

Engeström, Y. (1999). Activity theory and individual and social transformation. In. Y. Engeström, R, Miettinen, \& R.-L. Punamäki (Eds.), Perspectives on Activity Theory (pp. 19-38). Cambridge: Cambridge University Press.

Halverson, C.A. (2002). Activity Theory and Distributed Cognition: Or What Does CSCW Need to DO with Theories? Computer Supported Cooperative Work, 11, 243-267.

Kaptelinin, V. (1996). Computer-Mediated Activity: Functional Organs in Social and Developmental Contexts. In B.A. Nardi (Ed.), Context and Consciousness. Activity Theory and Human-Computer Interaction (pp. 103-116). Cmbridge: MIT Press. 
Kuutti, K. (1996). Activity Theory as a Potential Framework for Human-Computer Interaction Research. In B.A. Nardi (Ed.), Context and Consciousness. Activity Theory and Human-Computer Interaction (pp. $17-$ 44). Cambridge: MIT Press.

Leontev, A.N. (1974). The problem of activity in psychology. Soviet Psychology, 13(2), 4-33.

Nielsen, J. (1993). Usability Engineering. San Diego: Academic Press.

Norman, D.A. (1988). The design of everyday things. Basic Books.

Norros, L. (2004). Acting under uncertainty. Espoo, Finland: VTT Technical Research Centre.

Perrow, C. (1984). Normal Accidents. Princeton, NJ: Princeton University Press.

Rabardel, P., \& Béguin, P. (2005). Instrument mediated activity: from subject development to anthropocentric design. Theoretical Issues in Ergonomics Science, 6(5), 429-461.

RNoN. 22nd FPB Squadron. 2006 [cited 2006 2006-02-16]. Available from: http://www.22mtb.com/english/ index.htm.

Vicente, K.J. (1999). Cognitive Work Analysis. Toward safe, productive, and healthy computer-based work. New Jersey: LEA.

Woods, D.D., \& Sarter, N.B. (2000). Learning From Automation Surprises and "Going Sour" Accidents. In N.B. Sarter, \& R. Amalberti (Eds.), Cognitive Engineering in the Aviation Domain (pp. 327-353). Hillsdale, NJ: Lawrence Erlbaum Associates.

\section{RÉSUMÉ}

Cette étude rend compte de l'utilisation de la théorie de l'activité comme support à un processus de conception. Des équipages de vedettes rapides de la marine royale norvégienne ont été observés au cours de navigation à grande vitesse en eaux côtières. L'unité de l'analyse était un équipage de cinq personnes pendant leur travail. L'activité a été considérée en tant qu'actions situées, déterminée par des outils, des objets et des contraintes. Le cadre de la théorie de l'activité a été utilisé pour élaborer un langage de conception englobant les questions concernant la conception et la navigation. À partir des résultats obtenus, un prototype d'une commande de pilotage automatisée a été réalisé. Nous suggérons que la théorie de l'activité change la centration du processus de conception : des propriétés techniques des artefacts vers la manière dont ils sont utilisés comme outils médiateurs de l'activité.

MOTS-CLÉ

Théorie de l'activité, conception, bateaux, navigation.

\section{RESUMEN}

La teoría de la actividad como soporte para el diseño de equipos de navegación. Este estudio da cuenta de la utilización de la teoría de la actividad como soporte para un proceso de diseño. Se han realizado observaciones de tripulaciones de lanchas rápidas de la real marina noruega, en el transcurso de navegación a gran velocidad en aguas territoriales. La unidad de análisis fue una tripulación de cinco personas durante su trabajo. La actividad fue considerada en tanto que acciones situadas, determinadas por las herramientas, los objetos y las dificultades. Para poder elaborar un lenguaje de diseño que englobe les cuestiones referidas al diseño y a la navegación, se ha utilizado el enfoque de la teoría de la actividad. A partir de los resultados obtenidos, se ha realizado un prototipo de dispositivo de pilotaje automático. Concluimos señalando que, durante el proceso de diseño, la teoría de la actividad desplaza el foco de atención. Mientras que el diseño tradicionalmente se centra sen la calidad técnica de los artefactos, 
la teoría de la actividad hace foco en la manera en que los artefactos son utilizados como herramientas mediadoras de la actividad.

Palabras-clave

Teoría de la actividad, diseño, embarcaciones, navegación. 